ISSN: 0213-2079 - ISSN electrónico: 2386-3889

DOI: https://doi.org/10.14201/shhmo20184011929

\title{
PRESENTACIÓN. LOS LÍMITES DE LA OBEDIENCIA EN EL MUNDO HISPÁNICO DE LA EDAD MODERNA: DISCUR- SOS Y PRÁCTICAS
}

\section{The limits of obedience in the Hispanic world: speeches and practices}

\author{
Doris MORENO \\ Universidad Autónoma de Barcelona \\ Correo-e: Doris.Moreno@uab.es \\ ORCID: 0000-0003-2880-9533
}

Los años veinte del siglo xvi son el canto de cisne de un experimentalismo religioso y una fluidez doctrinal que se vieron constreñidos progresivamente, a medida que con mayor precisión se definía la identidad católica y se fortalecían las bases de una estructura jerárquica y de un sistema de poder ligado a un papado fuerte y exigente en términos de uniformidad doctrinal y pastoral. Este proceso fue al mismo tiempo de carácter interno y externo, en relación y confrontación con los pujantes estados nacionales. En paralelo, desde el siglo xv había crecido el espacio de la conciencia individual con valor autorreferencial como principio de autoridad, de modo que iglesias y estados comprendieron la importancia de sujetar el interior de los individuos, por «cadenas» que hicieran de ellos fieles y súbditos sumisos a su autoridad ${ }^{1}$. Obediencia y autoridad se configuraron como problemas de primer orden en la convulsa historia de la Europa del xvi. Los debates planteaban una cuestión nuclear: si las leyes positivas obligaban en conciencia bajo

* El trabajo y la coordinación de este informe son resultado de las actividades del Proyecto de Investigación de referencia HAR2014-5234-C5-1-P del Ministerio de Economía, Industria y Competitividad del Gobierno de España.

1. Prodi, P.: Una historia de la justicia. De la pluralidad de fueros al dualismo moderno entre conciencia y derecho. Buenos Aires, 2008, pp. 194 y ss.; Lavenia, V.: L'infamia e il perdono. Tributi, pene e confessione nella teologia morale Della prima età moderna. Bolonia, 2000. 
pecado mortal, es decir, si la obediencia política tenía un carácter moral o no en el marco de la progresiva diferenciación entre los fueros religioso y secular. El deber de la obediencia como pecado. Significativo y ejemplificador de esta afirmación es el salto cualitativo que marcó en 1469 la publicación de la bula In Coena Domini por el Papa Paulo II, al incluir entre sus anatemas el desacato o desobediencia a la autoridad papal. El anatema tenía un altísimo valor político-religioso. Así, la desobediencia se acercaba progresivamente al campo de la herejía y la obediencia se situaba en el campo de la ortodoxia ${ }^{2}$.

En los últimos años, y al amparo de la aceptación (no siempre crítica) de los conceptos de confesionalización y disciplinamiento social, ha emergido un renovado interés por el estudio de la imposición y la interiorización de la obediencia a la norma por parte de los individuos en el mundo moderno. Recientemente, desde la historia política (Rafael Valladares, Beatriz Cárceles de Gea, Alicia Esteban Estríngana...) y la historia religiosa (S. Mostaccio...) o ambas simultáneamente (Prodi, Lavenia...), se ha subrayado la importancia del concepto de obediencia a caballo entre estrategias de coacción y persuasión. Se han apuntado las diferentes semánticas del concepto a partir de su evolución histórica: desde las tradiciones medievales (del «obedece pero no se cumple»), a la reelaboración tridentina (la obediencia a Dios y a la Iglesia vinculada al cuarto mandamiento), a la obediencia jesuítica (ciega), o la obediencia lipsiana (obediencia como sinónimo de disciplina). Y se han estudiado el conjunto de prácticas y estrategias que se encaminaron a inculcar en el corazón de los fieles la obediencia a la autoridad, desde la instrucción doctrinal, la predicación, la administración de los sacramentos o el culto a los santos, sin olvidar el confesionario. Porque el vínculo de la obediencia debía soldar los corazones, las almas y los cuerpos a la autoridad ${ }^{3}$.

2. Para comprender mejor el papel instrumentalizador de la bula In Coena Domini y cómo su uso sancionó la desobediencia al papado como herejía en las décadas siguientes, ver GianNinI, M. C.: «"El martillo sobre el ánima”. Filippo II e la bolla In Coena domini nell’Italia spagnola tra religione e sovranità (1568-1570)», en Felipe II (1527-1598): Europa y la monarquía católica, Martínez Millán, José (dir.), vol. III, 1998, pp. 251-270; y Brambilla, E.: Alle origine del Sant'Uffizio: Penitenza, confessione e giustizia spirituale dal medievo al XVI secolo. Bolonia, 2000 , pp. 257-260.

3. Valladares Ramírez, R.: «Fidelidad, lealtad y obediencia. Tres conceptos en la monarquía de los Austrias», en Quirós Rosado, R. y Bravo Lozano, C. (coord.): Los hilos de Penélope: lealtad y fidelidad en la Monarquía de España, 1648-1714. Valencia, Albatros ediciones, 2015, pp. 21-38; id.: «El problema de la obediencia en la Monarquía Hispánica, 1540-1700», en Esteban Estríngana, A. (ed.): Servir al Rey en la Monarquía de los Austrias. Madrid, Sílex, 2012, pp. 121-146; CÁRCELES DE GEA, B.: Fraude y desobediencia fiscal en la Corona de Castilla en el siglo XVII (1621-1700). Valladolid, Junta de Castilla y León, 2000; id.: «La revolución liberal y la obediencia absoluta a la ley (1812)», Bulletin hispanique, Vol. 
La obediencia está en el centro de la Reforma católica y en el corazón de los objetivos políticos de la Monarquía. Se ha dicho que «Madrid se conformó entre fines del siglo xvi y fines del siglo xviI en un conjunto de escenarios donde se rendía culto a la obediencia» ${ }^{4}$. El papel de la Compañía de Jesús en la educación de las elites y su dirección de conciencia extendió socialmente el discurso sobre la obediencia y el valor de su particular visión, la obediencia ciega. El discurso religioso se trasladó al campo de la política.

Buscando obediencia ciega, el Conde-Duque de Olivares no dejó de encontrar, por contraste, su opuesto. En los años treinta del siglo xvir, el valido de Felipe IV ya consideraba que la obediencia era una «disfunción patológica» de la Monarquía hispánica:

Señor, la falta de obediencia y tibieza de amor, y sobra de fines propios tiene hoy el servicio de S. M. en tal estado que, si no se remedia con gran cuidado y atención, todo irá a fondo... No tiene S. M. vasallo que no capitule con él cuanto quiere en mandándole algo, vendiéndose, como se vio en el de Cardona, en el de Villafranca, en D. Gonzalo, el de Leganés, en el de Castañeda, en Oñate, ahora en Don Cristóbal de Benavente, el de Feria, ahora los que van a Roma. Y, en efecto, todos: los chicos y los grandes... ${ }^{5}$.

En 1634 y a instancia de Olivares se creó la Junta de Obediencia con el propósito de trabajar para reducir el elevado grado de desobediencia que se observaba en los altos cargos de la administración. La crisis de 1640 fue, a los ojos de Olivares, fundamentalmente, una crisis de obediencia.

¿Fue solo un problema de las elites? Parece que no. En los últimos años algunos trabajos han coincidido en ampliar el diagnóstico del Conde-Duque al conjunto de españoles. Ruth MacKay o Helen Nader han puesto en evidencia las múltiples formas en las que los súbditos castellanos negociaron y/o resistieron legítimamente

103, N. ${ }^{\circ}$ 1, 2001, pp. 127-154; Esteban Estríngana, A.: «El servicio, paradigma de relación política en los siglos XVI y XVII», en Esteban Estríngana, A.: Servir al rey en la Monarquía de los Austrias: Medios, fines y logros del servicio al soberano en los siglos XVI y XVII. MADRID, Sílex, 2012, pp. 11-45, id.: «El mito de Gedeón y la noción de servicio. De soberanía y sujeción política entre los siglos Xvi y xviI», en Esteban Estríngana, A.: Servir al rey, pp. 87-118; id.: Decidir la lealtad. Leales y desleales en contexto (ss. XVI-XVII), Aranjuez, 2017; Mostaccio, S.: Early Modern Jesuits Between Obedience and Conscience, Ashgate Publishing, 2013; Prodi, P.: Op. cit. Lavenia, V.: Op. cit.

4. Valladares, R.: «El problema de la obediencia», p. 140.

5. Memoriales y cartas del Conde Duque de Olivares, ed. John H. Elliot y José F. DE LA PeÑa, tomo II, Madrid, 1981, pp. 75-76; Aldea Vaquero, Q.: «Un noble español del Barroco. Don García de Toledo, VI Marqués de Villafranca (1585-1649)», Cuadernos de Historia del Derecho, vol. extr., 2004, 15-32, p. 17. 
a la creciente y brutal presión de la Monarquía para extraer recursos económicos y humanos en el contexto de la crisis de mediados del siglo xvir. Como resultado de sus investigaciones, estas historiadoras han podido hablar de la «naturaleza democrática del absolutismo castellano» o caracterizar a la Monarquía hispánica de «estado híbrido» por la delicada convivencia en equilibrio de elementos opuestos (tradición y modernidad, centralización y particularismo...) y la capacidad del estado para tolerar/soportar estas conductas 6 . Asimismo, nuestro propio grupo de investigación lleva trabajando en estos aspectos desde hace varios años, profundizando en algunas líneas especialmente novedosas, contribuyendo a dibujar un cuadro de la Reforma Católica mucho más matizado y rico, atendiendo a la participación de los sujetos en el proceso histórico mediante tácticas y estrategias, micro-resistencias individuales y colectivas, cierta «indisciplina crónica», que modulaban las normas, que incidían sobre la actitud de las autoridades a la hora de imponerlas ${ }^{7}$. Así, la resultante de Trento no fue tanto el modelo soñado por sus definidores como el producto de la relación dinámica y fluctuante entre obediencia y desobediencia.

En este dosier, nuestro propósito es abordar los límites de la Reforma católica en el mundo Hispánico a lo largo de los siglos modernos (XVI-XVIII) desde la perspectiva de la relación dinámica entre obediencia y desobediencia. Nos proponemos subrayar críticamente los límites de la obediencia impuesta por el programa confesionalizador, de las estrategias seguidas para conformar las conciencias y los comportamientos de los fieles-súbditos. Y hacerlo desde una perspectiva sociocultural que aborde las tácticas y estrategias de individuos y corporaciones para, por un lado, dibujar con sus conductas los límites y porosidades de un objetivo que se pretendía absoluto y, por otro, subrayar hasta qué punto esas conductas provocaron actitudes tolerantes y cambiaron a la práctica la fisonomía de la Reforma católica.

El primer artículo, de quien firma esta presentación, ofrece una aproximación a las prácticas de disimulo de los círculos protestantes españoles de mediados del siglo xvi: las autolegitimaciones desarrolladas por sus actores, las formas que

6. MacKay, R.: Los limites a la autoridad real: resistencia y obediencia en la Castilla del siglo XVII, Valladolid: Junta de Castilla y León, 2007; NADER, H.: Liberty in Absolutism Spain: The Habsburg sale of Towns, 1516-1700. Baltimore, 1990.

7. Me limito a apuntar aquí únicamente dos resultados destacados de esta vía de trabajo seguida por el conjunto de proyectos que trabajamos coordinadamente en esta línea. En primer lugar, el dosier coordinado por Atienza López, A.: «De reacciones, de tolerancias, de resistencias y de polémicas. Las «grietas» de la Contrarreforma y los límites del disciplinamiento social» y publicado en Hispania, vol. 74, n. 248, 2014, con colaboraciones de E. SERrANO; J. L. Betrán; J. Pardo-Tomás; M. Peña y D. Moreno, y más recientemente, Betrán Moya, J. L.; Hernández, B. y Moreno, D. (eds.): Identidades y fronteras culturales en el mundo ibérico en la Edad Moderna. Bellaterra, 2016. 
adoptaron y el incipiente desarrollo de una identidad diferenciada que solo maduró en los individuos que pudieron exiliarse. En el particular sustrato social hispano cuajaron unas prácticas del disimulo transmitidas generacionalmente, que pudieron heredar algunos de los procesados de origen converso. Asimismo, estos individuos fueron creadores de una suerte de teología de la cotidiano en la medida en que una parte de su disimulo consistía en autolegitimar en el día a día la práctica externa de la fe desde la creciente distancia con la fe vivida interiormente, situándose en los límites de la obediencia al poder establecido y su ortodoxia.

Eliseo Serrano plantea, ya de lleno en el marco de la Reforma católica, en el siglo XVII, las normas y estrategias emitidas por Roma para controlar directamente el proceso de concesión de santo patrono o santo protector, insertando este aspecto en el amplio programa tridentino para depurar y controlar la santidad. A la construcción de santidades, con el florilegio de episodios imprescindibles para arropar al personaje, tales como milagros, sanidades y dones especiales, se dedicaron muchos, estimulados por intereses variopintos, de las órdenes religiosas respectivas, de autoridades locales deseosas de cobijarse bajo el prestigio de figuras memorables, de intereses nobiliarios y de la propia Monarquía. La devoción popular actuó de acicate para unos y otros, y la fiebre por la posesión de reliquias da la justa medida de hasta qué punto confluyeron intereses sociales diversos en una dinámica sacralizadora de territorios y comunidades locales. Fue justamente esa variedad de intereses, a veces confluyentes, a veces en pugna, la que determinó la flexibilización de la norma. El profesor Serrano expone dos casos, el de Pedro Regalado y Rosa de Lima para ilustrarnos sobre ello. En el primero, fue la persistencia de la ciudad de Valladolid, extendida a otros obispados castellanos, y con el apoyo de la Monarquía, la que determinó el «triunfo» ya en el siglo xviII de una iniciativa que, iniciada dos siglos antes, parecía destinada al fracaso. En el segundo caso, se hace todavía más evidente cómo se abrió la puerta a las excepciones en nombre de intereses político-religiosos de profundo calado: el patronazgo de santa Rosa de Lima no se ajustaba a los modelos propuestos por la Santa Sede y requirió de autorizaciones expresas para el inicio de la canonización. Fue incluso nombrada patrona de la Ciudad de los Reyes, su ciudad natal, y del Perú en 1669, antes de ser canonizada, algo expresamente prohibido en 1630. Pero, como apunta el profesor Serrano, la necesidad de una santidad aglutinadora de los territorios americanos, de una primera santa americana, y los intereses de las órdenes religiosas en el territorio jugaron un papel crucial en la apertura de una excepción que muestra a las claras cómo la obediencia a la normativa vaticana podía ser negociada.

El trabajo de Ángela Atienza atiende a los límites de la obediencia en el mundo conventual femenino, en este caso en el marco de la Corona de Aragón a mediados 
del siglo Xvir, completando un puzle que ya tenía valiosas piezas bien colocadas y que completa una visión de conjunto de esta cuestión ${ }^{8}$. La profesora Atienza analiza la problemática de la imposición de la clausura desde la perspectiva de los instrumentos y argumentaciones que las mismas monjas hicieron aflorar por los caminos aceptados, como la correspondencia, para de manera abierta mostrar su disentimiento y los límites de la imposición de la norma por la vía de obediencia. El primer límite, sin embargo, era la conciencia de la propia autoridad de que lo que se impone no dura; es decir, que la persuasión era fundamental para que la obediencia obligase de manera perdurable y significativa. Esta conciencia obligaba, por lo menos, a la escucha de los argumentos en contra de la clausura de las monjas disidentes. La obediencia se muestra así como una acción multidireccional en un ámbito dinámico y fluctuante. Y la exigencia de obediencia se enmascara además en los niveles intermedios de la pirámide social. En la cascada piramidal de autoridad, la obediencia como discurso no desciende incólume, sino que se renegocia en cada nivel dependiendo del estatus de sus agentes y sujetos pacientes, de su grado de resistencia. Como vemos en este artículo, los niveles intermedios asumían un doble discurso, de acatamiento al superior y, al mismo tiempo, tolerancia comprensiva de las resistencias del inferior.

Las monjas de varios conventos catalanes y aragoneses argumentaron de manera muy fundamentada contra un breve papal de 1664 en el que se ordenaba la observancia de una serie de medidas destinadas a establecer la más estricta clausura. En primer lugar, distinguían entre desobediencia voluntaria, sinónimo de rebeldía, y desobediencia involuntaria, producida por la imposibilidad de obedecer. Ellas se situaban, por supuesto, en este segundo ámbito. ¿Y qué factores hacen imposible la obediencia a unos decretos emanados de las más altas autoridades eclesiásticas y políticas? Las monjas exponen hasta tres argumentos de indudable peso en el marco político-religioso de la época. El primero es el que se mueve en el ámbito de la hermenéutica jurídica y religiosa: al entrar en el convento las monjas aceptaban unas reglas de juego explícitas y la institución y ellas mismas se comprometían con juramento a cumplirlas. Un cambio de esas reglas solo podría obligar a las que entrasen en religión a partir de la aplicación de la nueva norma. El segundo

8. Atienza López, Á.: «Lo reglado y lo desarreglado en la vida de los conventos femeninos de la España Moderna», en Peña Díaz, M. (dir.): La vida cotidiana en el Mundo Hispánico (ss. XVI-XVIII). Madrid, 2012, pp. 445-465; AtienZa LópeZ, Á.: «Las grietas de la clausura tridentina. Polémicas y limitaciones de las políticas de encerramiento de las monjas... todavía con Felipe V», Hispania, 248, 2014, pp. 807-834; Atienza López, Á.: «Mujeres y hombres de Iglesia. Orden y desorden en torno a la imposición de la clausura tridentina», ponencia presentada en XIV reunión científica de la Fundación Española de Historia Moderna, Zaragoza, junio 2016. En prensa. 
argumento, aparentemente de tipo económico, confrontaba a las autoridades eclesiásticas con la esencia de sus funciones como protectores: para las monjas, la clausura estricta que se pretendía imponer amenazaba ampliamente su supervivencia vital. El tercer argumento entraba en el ámbito de la moral criticando el juicio que había motivado la orden de clausura: los excesos de algunas monjas no podían traducirse en una norma para el conjunto. Como concluye la profesora Atienza, la defensa bien argumentada de las monjas puso en evidencia los límites a la obediencia y su resistencia abrió el camino a la reconsideración y la modulación de la norma, cuando no directamente al disimulo tolerante de mal menor.

El artículo de Rosa M. Alabrús es un fascinante estudio de caso, el de una mujer extraordinaria, superdotada, exhibida por su padre como niña prodigio. Bajo la tutela paterna, Juliana Morell, con catorce años, expone tesis de filosofía en la Universidad en Lyon, conoce el latín, griego, hebreo, árabe, caldeo, italiano y francés, además de catalán y castellano. El padre quería promocionar a su hija esperando, quizá, resarcirse de una grave situación económica a través de un matrimonio ventajoso. Ante esa tesitura, la muchacha decide entrar en religión pese a la oposición del padre. Es en el ámbito conventual donde Morell pudo canalizar sus capacidades bajo el signo paradójico del silencio y la obediencia. Silencio prudente para hablar. Silencio prudente para escribir: fundamentalmente traducciones de textos monásticos con comentarios personales. Y obediencia a los superiores que impone ella misma como priora a las novicias del convento. ¿Es Juliana Morell ejemplo de sumisión al arquetipo de la monja contrarreformista? ¿Su opción por el convento fue la elección consciente del mal menor frente a la alternativa de mujer casada y sometida que le ofrecía el padre? Lo cierto es que bajo el signo del silencio y la obediencia Morell todavía encontró margen para desarrollar sus capacidades intelectuales, sublimadas en la dimensión espiritual, y en una exigencia creciente de rigorismo moral en el marco de una Francia confesionalmente dividida. Entre el acatamiento al varón, fuese padre o marido, o a la autoridad eclesiástica, Morell optó por la segunda opción creyendo que ahí todavía tenía margen de desarrollo antes de tocar el límite de la (des)obediencia.

El texto de José Luis Betrán aborda los instrumentos tridentinos de disciplinamiento del clero: obispos, sínodos, el espacio bisagra en el que se encuentran las máximas autoridades de la diócesis y los curas del pueblo, los rectores parroquiales, los representantes de las órdenes religiosas en el territorio, la baja iglesia, que antes de Trento ha formado parte de la comunidad por sus orígenes, por su identificación con la cultura popular, y que ahora, bajo el impulso tridentino debe asumir un liderazgo que le distingue de la comunidad, que le sacraliza: en las vestiduras, en la forma de hablar, en la forma de presentarse a sí mismo, de relacionarse con su 
«rebaño», desde los espacios sacramental a las fiestas populares ${ }^{9}$. Esa distinción pasa por una ejemplaridad moral y social, vinculada a la imagen del «buen pastor», que obliga a un programa de reeducación en el estándar ahora definido. También en este ámbito la obediencia, sea por convicción o por obligación, es clave para que el programa tridentino tenga éxito. Así, los que quieran iniciar el camino del sacerdocio tendrán que aprender a leer y escribir, iniciarse en las rutinas del latín e incluso el griego, aprender a hablar en el púlpito y a escuchar en el confesionario; deberán tomar conciencia de que la obediencia en su estado también implica no violar el voto de castidad, y por tanto tener mancebas, ser hombres de paz y en consecuencia no llevar armas, cuidar su lenguaje y utilizar las palabras y los silencios en las formas establecidas para su oficio... Las resistencias del clero a encajar en este modelo contrarreformista es lo que se plantea en el articulo de José Luis Betrán. Más allá de la norma y la construcción de los modelos ejemplarizantes a lo largo de la Edad Moderna, la realidad cotidiana vivida por el clero parroquial y sus fieles muestra los límites y, en este caso, la transgresión, de la obediencia entre un clero que se resiste a la ejemplaridad, que está más cerca de la irreverencia de la comunidad eclesial que administra que de la jerarquía eclesiástica que impone.

El artículo de Manuel Peña Díaz nos traslada a otro espacio límite de las (des)obediencias. El exceso de vino y risas entre el pueblo, la embriaguez (que no siempre es por felicidad ni genera felicidad, sino el deseo de huida respecto a las angustias cotidianas) situaba a los individuos en un territorio fronterizo en el que era posible soñar con la libertad de la servidumbre y hasta creer que se había alcanzado. Esa «peligrosa» combinación de vino excesivo y risas, multiplicada en la sociabilidad de las tabernas, hacía la vida más humana, según decía Séneca y nos recuerda Manuel Peña. Curiosamente, los teólogos casuistas ponían puertas a esa humanidad en la habitación cerrada de la teología moral más rígida. En las numerosas excepciones a la condena moral de los excesos por el consumo de vino, que convertía pecados mortales en veniales, y veniales en conductas legítimas, se diluía la gravedad en beneficio de la levedad. Y la risa, tan necesaria ayer y hoy para la supervivencia cotidiana, venía en ayuda de los hombres y mujeres del Antiguo Régimen constreñidos por la creciente llamada a la seriedad y gravedad, cuando no directamente sacralidad, de ceremonias, ritos y conductas. En este marco, la obediencia a la norma era importante, pero menos en la perspectiva micro, amparada

9. Betrán Moya, J. L.: «El pastor de almas: la imagen del buen cura a través de la literatura de instrucción sacerdotal en la Contrarreforma española», en SERrano, E.; Cortés, A. L. y Betrán, J. L. (eds.): Discurso religioso y Contrarreforma. Zaragoza, Institución Fernando el Católico, 2005, pp. 161-202. 
y legitimada por el comprensivo casuismo, agrietada por la búsqueda de días de vino y risas que hicieran soportable o quizá muy necesaria la «levedad del ser».

El conjunto de todos estos trabajos abunda, en definitiva, en la distancia entre la obediencia en su exigencia más estricta, y la desobediencia abierta. Lejos de ser una línea fina, podremos apreciar un amplio territorio por el que los súbditos de la Monarquía hispánica pudieron, a través de vías más o menos formales, expresar su disidencia respecto a la norma e influir para modificarla o abrir grietas de excepción. Constataremos también cómo ante la realidad de la indisciplina crónica generalizada, por ejemplo en el abuso del alcohol, los moralistas casuistas aliviaron la conciencia de los penitentes por la vía de la comprensión de las circunstancias, tiempo y lugar. Finalmente, nos aproximaremos al territorio de la obediencia externa de las ceremonias y rituales religiosos y la desobediencia interior, de la conciencia, legitimada por la vía de la resemantización y el silencio, un silencio rebelde que se intuye pero se escurre entre los dedos del historiador.

El tema de la (des)obediencia a la ley está de moda en nuestro tiempo. Es un debate muy antiguo, nuclear en todas las sociedades que se han pensado a sí mismas. Ya lo encontramos en Atenas y, desde ahí, ha corrido en paralelo con la historia de los hombres y las mujeres en sociedad. Al alba del siglo XXI se han abierto para algunos los tiempos de la desobediencia, la era de los indignados, ante un statu quo percibido como injusto o insoportable. Los súbditos de la Monarquía hispánica estudiados en las páginas que siguen actuaron individual y colectivamente en ese mismo territorios. No está demás, para concluir, invocar aquí la figura de Michel de Certeau delicadamente glosado por Roger Chartier: «las tensiones entre discurso de autoridad y voluntades rebeldes... atraviesan tanto nuestro presente como las sociedades del pasado. La historia es lugar de experimentación, manera de destacar las diferencias. Saber del otro, y por lo tanto de uno mismo» ${ }^{10}$.

\section{BibLIOGRAFÍA}

«De reacciones, de tolerancias, de resistencias y de polémicas. Las «grietas» de la Contrarreforma y los límites del disciplinamiento social» dosier coordinado por ATIENZA, Á. y publicado en Hispania, vol. 74, n. 248, 2014, con colaboraciones de E. SERrano, J. L. Betrán; J. Pardo-Tomás; M. Peña y D. Moreno.

Aldea Vaquero, Q.: «Un noble español del Barroco. Don García de Toledo, VI Marqués de Villafranca (1585-1649)», Cuadernos de Historia del Derecho, vol. extr., 2004, 15-32, p. 17.

10. Chartier, R.: «Michel de Certeau y lo cotidiano. Estrategias y tácticas», en PeÑA, M.: La vida cotidiana en el Mundo Hispánico (ss. XVI-XVIII). Madrid, Abada, 2012, pp. 21-27, p. 27. 
DORIS MORENO

PRESENTACIÓN. LOS LÍMITES DE LA OBEDIENCIA EN EL MUNDO HISPÁNICO DE LA EDAD MODERNA: DISCURSO Y PRÁCTICAS

Atienza López, Á.: «Las grietas de la clausura tridentina. Polémicas y limitaciones de las políticas de encerramiento de las monjas... todavía con Felipe V», Hispania, 248, 2014, pp. 807-834.

Atienza López, Á.: «Lo reglado y lo desarreglado en la vida de los conventos femeninos de la España Moderna», en Peña Díaz, Manuel (dir.): La vida cotidiana en el Mundo Hispánico (ss. XVI-XVIII). Madrid, 2012, pp. 445-465.

Atienza López, Á.: «Mujeres y hombres de Iglesia. Orden y desorden en torno a la imposición de la clausura tridentina», ponencia presentada en XIV reunión científica de la Fundación Española de Historia Moderna, Zaragoza, junio 2016. En prensa.

Betrán Moya, J. L.; Hernández, B. y Moreno, D. (eds.): Identidades y fronteras culturales en el mundo ibérico en la Edad Moderna. Bellaterra, 2016.

BETRÁn MoyA, J. L.: «El pastor de almas: la imagen del buen cura a través de la literatura de instrucción sacerdotal en la Contrarreforma española», en Serrano, E.; Cortés, A. L. y Betrán, J. L. (eds.): Discurso religioso y Contrarreforma. Zaragoza, Institución Fernando el Católico, 2005, pp. 161-202.

Brambilla, E.: Alle origine del Sant'Uffizio: Penitenza, confessione e giustizia spirituale dal medievo al XVI secolo. Bolonia, 2000, pp. 257-260.

CÁrceles DE GEA, B.: «La revolución liberal y la obediencia absoluta a la ley (1812)», Bulletin hispanique, Vol. 103, N. ${ }^{\circ}$ 1, 2001, pp. 127-154.

CÁrceles de Gea, B.: Fraude y desobediencia fiscal en la Corona de Castilla en el siglo XVII (1621-1700). Valladolid, Junta de Castilla y León, 2000.

Chartier, R.: «Michel de Certeau y lo cotidiano. Estrategias y tácticas», en PeÑA, M.: La vida cotidiana en el Mundo Hispánico (ss. XVI-XVIII). Madrid, Abada, 2012, pp. 21-27.

Esteban Estríngana, A.: «El mito de Gedeón y la noción de servicio. De soberanía y sujeción política entre los siglos XVI y XVII», en Esteban Estríngana, A.: Servir al rey, pp. 87-118.

Esteban Estríngana, A.: Decidir la lealtad. Leales y desleales en contexto (ss. XVI-XVII), Aranjuez, 2017.

Esteban Estríngana, A.: «El servicio, paradigma de relación política en los siglos XVi y xviı», en Esteban Estríngana, A.: Servir al rey en la Monarquía de los Austrias: Medios, fines y logros del servicio al soberano en los siglos XVI y XVII. Madrid, Sílex, 2012, pp. 11-45.

Lavenia, V.: L'infamia e il perdono. Tributi, pene e confessione nella teologia morale Della prima età moderna. Bolonia, 2000.

MACKAY, R.: Los limites a la autoridad real: resistencia y obediencia en la Castilla del siglo XVII. Valladolid, Junta de Castilla y León, 2007.

Mostaccio, S.: Early Modern Jesuits Between Obedience and Conscience. Ashgate Publishing, 2013.

NAder, H.: Liberty in Absolutism Spain: The Habsburg sale of Towns, 1516-1700. Baltimore, 1990.

Prodi, P.: Una historia de la justicia. De la pluralidad de fueros al dualismo moderno entre conciencia y derecho. Buenos Aires, 2008. 
DORIS MORENO

PRESENTACIÓN. LOS LÍMITES DE LA OBEDIENCIA EN EL MUNDO HISPÁNICO DE LA EDAD MODERNA: DISCURSO Y PRÁCTICAS

Valladares Ramírez, R.: «El problema de la obediencia en la Monarquía Hispánica, 1540-1700», en Esteban Estríngana, A. (ed.): Servir al Rey en la Monarquía de los Austrias. Madrid, Sílex, 2012, pp. 121-146.

Valladares Ramírez, R.: «Fidelidad, lealtad y obediencia. Tres conceptos en la monarquía de los Austrias», en Quirós Rosado, R. y Brazo Lozano, C. (coord.): Los hilos de Penélope: lealtad y fidelidad en la Monarquía de España, 1648-1714. Valencia, Albatros ediciones, 2015, pp. 21-38. 